\title{
Research on Design Technology of TLA Modified Asphalt Mixture
}

\author{
Xinjun Feng ${ }^{*}, 1$ Xudong Zha ${ }^{1}$ and Peiwen $\mathrm{Hao}^{2}$ \\ ${ }^{1}$ School of Communication and Transportation Engineering, Changsha University of Science and Technology, \\ Changsha 410004, China \\ ${ }^{2}$ School of Highway, Chang'an University, Xi'an 710064, China
}

\begin{abstract}
Marshall Test design methods are used to design TLA modified asphalt mixture and base asphalt mixture respectively, and their pavement performance is tested. The results showed that there is a transforming coefficient of 1.15 between OAC of $40 \%$ TLA modified asphalt mixture and that of base asphalt mixture, and ultimate gradation of the TLA modified asphalt mixture is finer than previous gradation. TLA modified asphalt mixture has excellent high temperature stability, capacity of moisture-resistance damage and impermeability. So it can be applied to asphalt pavements engineering of expressway in China.
\end{abstract}

Keywords: TLA, modified asphalt mixture, mixture design, pavement performance.

\section{INTRODUCTION}

Trinidad Lake Asphalt (TLA) is the most famous natural asphalt in the world. Because TLA is natural material which was formed after full oxidation under the crustal pressure and high temperature in several ten million years, it has the advantage of high softening point, excellent thermostability, oxidation resistant capacity, oil resistant capacity, acid and alkali resistant capacity and so on [1-5]. As early as in 1880, TLA was used in Washington streets, and later it was mostly used in highway with heavy-traffic, airfield, bridge pavement, express way and son on. Furthermore, TLA was widely used in Britian and Germany, and it enhanced pavement's service life and reduced pavement's maintenance cost effectively [1, 4-5]. During 1970 and 1980, TLA was researched in China, and the test roads were paved in Beijing, Shanxi and Zhejiang, etc, which showed excellent pavement performance. But TLA wasn't popularized in China because it's high price and low price of chinese asphalt at that tiame. In recent years, China's economic strength has greatly increased, and prices of asphalt at home and abroad have significantly changed, and price of TLA modified asphalt is slightly lower than the price of SBS modified asphalt, furthermore, TLA modified asphalt has very good compatibility with petroleum asphalt and excellent pavement performance [69]. It is predicted that TLA modified asphalt will have good application prospect in China, therefore, the deep research on application technology of TLA modified asphalt mixture has important economic value and realistic significance.

\section{CHNICAL CHARACTERISTICS OF RAW MATERIALS AND PREPARATION OF TLA MODIFIED ASPHALT}

\subsection{Base Asphalt}

The base asphalt used in the research is ESSO A-70\#, and its main cynical characteristics are shown in Table $\mathbf{1}$, which meet the requirements specified specification.

*Address correspondence to this author at the School of Communication and Transportation Engineering, Changsha University of Science and Technology, Changsha 410004, China; Tel: +86-731-85258575; Fax: +86731-85258375; E-mail: fxjasphalt@yahoo.com.cn, fxjasphalt@sina.com
Table 1. Main Chnical Characteristics of Base Asphalt

\begin{tabular}{|c|c|c|c|c|}
\hline \multicolumn{2}{|r|}{ Items } & Units & $\begin{array}{c}\text { Test } \\
\text { Value }\end{array}$ & $\begin{array}{c}\text { Technical } \\
\text { Requirements }\end{array}$ \\
\hline \multicolumn{2}{|c|}{ Penetration $\left(25^{\circ} \mathrm{C}, 100 \mathrm{~g}, 5 \mathrm{~s}\right)$} & $0.1 \mathrm{~mm}$ & 64 & $60-80$ \\
\hline \multicolumn{2}{|c|}{ Softening point } & ${ }^{\circ} \mathrm{C}$ & 48.5 & $\geq 46$ \\
\hline \multirow{2}{*}{ Ductility } & $\left(10^{\circ} \mathrm{C}, 5 \mathrm{~cm} / \mathrm{min}\right)$ & \multirow{2}{*}{$\mathrm{cm}$} & 113.4 & $\geq 15$ \\
\hline & $\left(15^{\circ} \mathrm{C}, 5 \mathrm{~cm} / \mathrm{min}\right)$ & & $>150$ & $\geq 100$ \\
\hline \multicolumn{2}{|c|}{ Density $\left(15^{\circ} \mathrm{C}\right)$} & $\mathrm{g} / \mathrm{cm}^{3}$ & 1.035 & - \\
\hline
\end{tabular}

\subsection{Trinidad Lake Asphalt (TLA)}

Researches showed that TLA is composed of four materials as following: (1) Petroleum asphalt (Soluble part of carbon disulfides) account for 53\% 55\%, it contains 36\% soft asphalting and $18 \%$ asphalting. Soluble asphalt contains $67 \% \sim 70 \%$ soft asphalting and $30 \% \sim 33 \%$ asphalting; (2) Mineral powders (ash), about $33 \%$ to $38 \%$, are mainly composed of quartz and clay. Mineral particles are very fine, and $90 \%$ of them are smaller than $0.075 \mathrm{~mm}, 44 \%$ of them are smaller than $0.01 \mathrm{~mm}$. They are coral-like, under the high temperature function, light asphalt components can be inhaled into stoma; (3) $4.3 \%$ mineral combined water ; (4) $3.2 \%$ organic material (insoluble in carbon disulfides). Chnical characteristics of TLA was tested and shown in Table $\mathbf{2}$, which meet the requirements specified specification.

\subsection{Chnical Characteristics of TLA Modified Asphalt}

TLA modified asphalt is prepared in the laboratory according to the following methods : Heating base asphalt and TLA to $150^{\circ} \mathrm{C}$ and $160^{\circ} \mathrm{C}$ respectively, mixes up them according to 40:60 proportion, then enhances the temperature to $170{ }^{\circ} \mathrm{C}$ and stirs 30 minutes. Chnical characteristics of TLA modified asphalt was tested and shown in Table 3, which meet TMA-30 requirements specified specification. 
Table 2. Main Chnical Characteristics of TLA

\begin{tabular}{|c|c|c|c|}
\hline Items & Units & Test Value & $\begin{array}{c}\text { Technical } \\
\text { Requirements }\end{array}$ \\
\hline \hline Penetration $\left(25^{\circ} \mathrm{C}, 100 \mathrm{~g}, 5 \mathrm{~s}\right)$ & $0.1 \mathrm{~mm}$ & 2.7 & $0 \sim 5$ \\
\hline Softening point & ${ }^{\circ} \mathrm{C}$ & 99.6 & $\geq 90$ \\
\hline Ash content & $\%$ & 35.4 & $33 \sim 38$ \\
\hline Density $\left(25^{\circ} \mathrm{C}\right)$ & $\mathrm{g} / \mathrm{cm}^{3}$ & 1.381 & $1.3 \sim 1.5$ \\
\hline $\begin{array}{c}\text { Penetration ratio after } \\
\text { thin-film oven test }\end{array}$ & $\%$ & 74 & 50 \\
\hline
\end{tabular}

\subsection{Aggregate}

The coarse aggregate and fine aggregate used in the research are both granite gravel produced in Hongda quarry of Zhuhai, Guangdong providence. Their main cynical characteristics are shown in Tables $\mathbf{4}$ and $\mathbf{5}$, which meets the requirements, specified specification.

\subsection{Filling}

The filling is Xinhui 32.5 cement produced in Yunan, Guangdong province.

\section{RESEARCH ON METHOD OF TLA MODIFIED ASPHALT MIXTURE DESIGN}

\subsection{Design of Mineral Aggregate Gradation Composition}

AC-13C which "Technical Specification for Construction of Highway Asphalt Pavements"(JTG F40-2004) put forward was used as mineral aggregate gradation of the top surface layer of the First Loop Expressway of Foshan City. In order to guarantee the anti-rut capacity at high temperature of asphalt mixture, simultaneously give attention to the crack resistance at low temperature, when determine the design gradation, base on the median of AC13 gradation, we reduce amount of $9.5 \sim 16 \mathrm{~mm}$ coarse aggregate and below $0.6 \mathrm{~mm}$ fine aggregate, and increase amount of the medium size aggregate, so as to form the "S" gradation curve. At the same time, considering 40\% TLA modified asphalt contains $12.8 \%$ ash, so passing rate of $0.075 \mathrm{~mm}$ is controlled less than or equal to median of gradation, which ensure the final gradation of asphalt mixture is nearby the medium of gradation. Four size particles of aggregates and one size particle of padding were sampling and screened, and mineral aggregates gradation composition was designed with the compotator methods. Aim gradation and design gradation of mineral aggregates mixture are shown in Table $\mathbf{6}$ and Fig. (1).

\subsection{Determine of Optimum Oil-Stone Rate}

In order to comparison study the mixture design technology upon TLA modifield asphalt mixture and base asphalt mixture, marshall test design methods are used to determined optimum oil-stone rate of $40 \%$ TLA modified asphalt mixture and base asphalt mixture respectively.

\section{(1) Range of Optimum Oil-Stone Rate}

According to previous construction experience, feasible range of oil-stone rate of ordinary asphalt mixture $\mathrm{AC}-13 \mathrm{C}$ is $4.0 \% \sim 6.0 \%$. But $40 \%$ TLA modified asphalt it contains $12.8 \%$ ash, so oil-stone rate of $40 \%$ TLA modified asphalt mixture must be increased, and there must be a transform coefficient between the optimum oil-stone rates. The transform coefficient can be got by calculation: Asphalt Content of $40 \%$ TLA modified asphalt is equal to $87.2 \%$ (1$12.8 \%$ ), that is to say, a piece of base asphalt is equal to 1.15 piece of $40 \%$ TLA modified asphalt. So range of oil-stone rate of $40 \%$ TLA modified asphalt mixture AC-13C should be $4.5 \% \sim 6.5 \%$, and it was also be adapted to in base asphalt

Table 3. Cynical Characteristics of TLA Modified Asphalt

\begin{tabular}{|c|c|c|c|c|}
\hline \multicolumn{2}{|c|}{ Items } & Units & Test Value & TMA-30 Reference Technical Requirement \\
\hline \multirow{3}{*}{ Penetration } & $15^{\circ} \mathrm{C}$ & $0.1 \mathrm{~mm}$ & 7.8 & \\
\hline & $25^{\circ} \mathrm{C}$ & $0.1 \mathrm{~mm}$ & 27.8 & $20 \sim 40$ \\
\hline & $30{ }^{\circ} \mathrm{C}$ & $0.1 \mathrm{~mm}$ & 49.2 & \\
\hline \multicolumn{2}{|c|}{ Correlation coefficient } & & 0.999 & \\
\hline \multicolumn{2}{|c|}{ Penetration index PI } & & -1.84 & \\
\hline \multicolumn{2}{|c|}{ Softening point } & ${ }^{\circ} \mathrm{C}$ & 56.0 & \\
\hline \multicolumn{2}{|c|}{ Ductility $25^{\circ} \mathrm{C}$} & $\mathrm{cm}$ & 70.1 & \\
\hline \multicolumn{2}{|c|}{ Ash content } & $\%$ & 12.8 & $7.5 \sim 19.5$ \\
\hline \multicolumn{2}{|c|}{ Viscosity, $135^{\circ} \mathrm{C}$} & $\mathrm{Pa} \cdot \mathrm{s}$ & 0.95 & $\leq 4.0$ \\
\hline \multicolumn{2}{|c|}{ Relative density $\left(25^{\circ} \mathrm{C}\right)$} & $\mathrm{g} / \mathrm{cm}^{3}$ & 1.133 & \\
\hline \multirow{5}{*}{ Thin-film oven test } & Mass defect & $\%$ & -0.49 & \\
\hline & Penetration $25^{\circ} \mathrm{C}$ & $0.1 \mathrm{~mm}$ & 22.3 & \\
\hline & Penetration ratio & $\%$ & 80.2 & $\geq 58$ \\
\hline & Softening point increment & ${ }^{\circ} \mathrm{C}$ & 3.6 & \\
\hline & Ductility ratio & $\%$ & 89.3 & \\
\hline
\end{tabular}


mixture in order to compare their physics mechanics performance.

Table 4. Main Chnical Characteristics of Coarse Mineral Aggregate

\begin{tabular}{|c|c|c|c|}
\hline Items & Units & $\begin{array}{c}\text { Test } \\
\text { Value }\end{array}$ & $\begin{array}{c}\text { Technical } \\
\text { Requirements }\end{array}$ \\
\hline \hline Crush value & $\%$ & 15.1 & $\leq 28$ \\
\hline Los Angeles abrasion loss & $\%$ & 7.3 & $\leq 30$ \\
\hline Apparent specific gravity density & - & 2.7 & $\geq 2.5$ \\
\hline Water-absorptivity & $\%$ & 0.8 & $\leq 3.0$ \\
\hline Ruggedness & $\%$ & 1.5 & $\leq 12$ \\
\hline Soft rock content & $\%$ & 2.5 & $\leq 5$ \\
\hline Needle flaky grain content & $\%$ & 1.9 & $\leq 18$ \\
\hline Adhesion with modified asphalt & grade & 5 & $\geq 5$ \\
\hline
\end{tabular}

Table 5. Main Chnical Characteristics of Fine Aggregate

\begin{tabular}{|c|c|c|c|}
\hline Items & Units & $\begin{array}{c}\text { Test } \\
\text { Value }\end{array}$ & $\begin{array}{c}\text { Technical } \\
\text { Requirements }\end{array}$ \\
\hline \hline $\begin{array}{c}\text { Apparent specific } \\
\text { gravity density }\end{array}$ & - & 2.68 & $\geq 2.5$ \\
\hline Ruggedness ( $>0.3 \mathrm{~mm}$ part) & $\%$ & 1.3 & $\leq 12$ \\
\hline Granulated substance equivalent & $\%$ & 70.3 & $\geq 60$ \\
\hline
\end{tabular}

\section{(2) Marshall Test Results and Discussion}

$40 \%$ TLA modified asphalt mixture and base asphalt mixture were produced respectively at five different oil-stone rate $(4.5 \%, 5.0 \%, 5.5 \%, 6.0 \%$ and $6.5 \%)$, and the Marshall specimens were prepared with Marshall Compaction machine. Then bulk density, Marshall Stability and flow value of the specimens were tested, and volume of air voids, voids filled with asphalt, voids in mineral aggregate of them

Table 6. Mineral Aggregate Gradation Composition of AC-13C

\begin{tabular}{|c|c|c|c|c|c|c|c|c|c|c|c|}
\hline \multirow{2}{*}{$\begin{array}{l}\text { Sieve Sizes }(\mathrm{mm}) \\
\text { Gradation }\end{array}$} & \multicolumn{10}{|c|}{ Passing Rate (\%) } & \multirow{2}{*}{ Proportion (\%) } \\
\hline & 16.0 & 13.2 & 9.5 & 4.75 & 2.36 & 1.18 & 0.6 & 0.3 & 0.15 & 0.075 & \\
\hline $10 \sim 15 \mathrm{~mm}$ detritus & 100 & 87.8 & 5.5 & 0.7 & 0.7 & 0.7 & 0.7 & 0.7 & 0.7 & 0.6 & 22 \\
\hline $5 \sim 10 \mathrm{~mm}$ detritus & 100 & 100 & 87 & 2.8 & 0.7 & 0.7 & 0.7 & 0.7 & 0.7 & 0.7 & 24 \\
\hline $3 \sim 5 \mathrm{~mm}$ detritus & 100 & 100 & 100 & 86.6 & 12.9 & 6.4 & 4.4 & 3.6 & 3.1 & 2.6 & 22 \\
\hline $0 \sim 3 \mathrm{~mm}$ Stone chips & 100 & 100 & 100 & 100 & 91.1 & 74.3 & 57.1 & 39.9 & 22.8 & 11.7 & 30 \\
\hline cement & 100 & 100 & 100 & 100 & 100 & 100 & 100 & 100 & 99.8 & 97.2 & 2 \\
\hline Upper limit of gradation & 100 & 100 & 85 & 68 & 50 & 38 & 28 & 20 & 15 & 8 & \\
\hline Lower limit of gradation & 100 & 90 & 68 & 38 & 24 & 15 & 10 & 7 & 5 & 4 & \\
\hline Median of gradation & 100 & 95 & 76.5 & 53 & 37 & 26.5 & 19 & 13.5 & 10 & 6 & \\
\hline Compound gradation & 100 & 97.3 & 76.2 & 51.9 & 32.5 & 26.0 & 20.4 & 15.1 & 9.8 & 6.3 & 100 \\
\hline
\end{tabular}

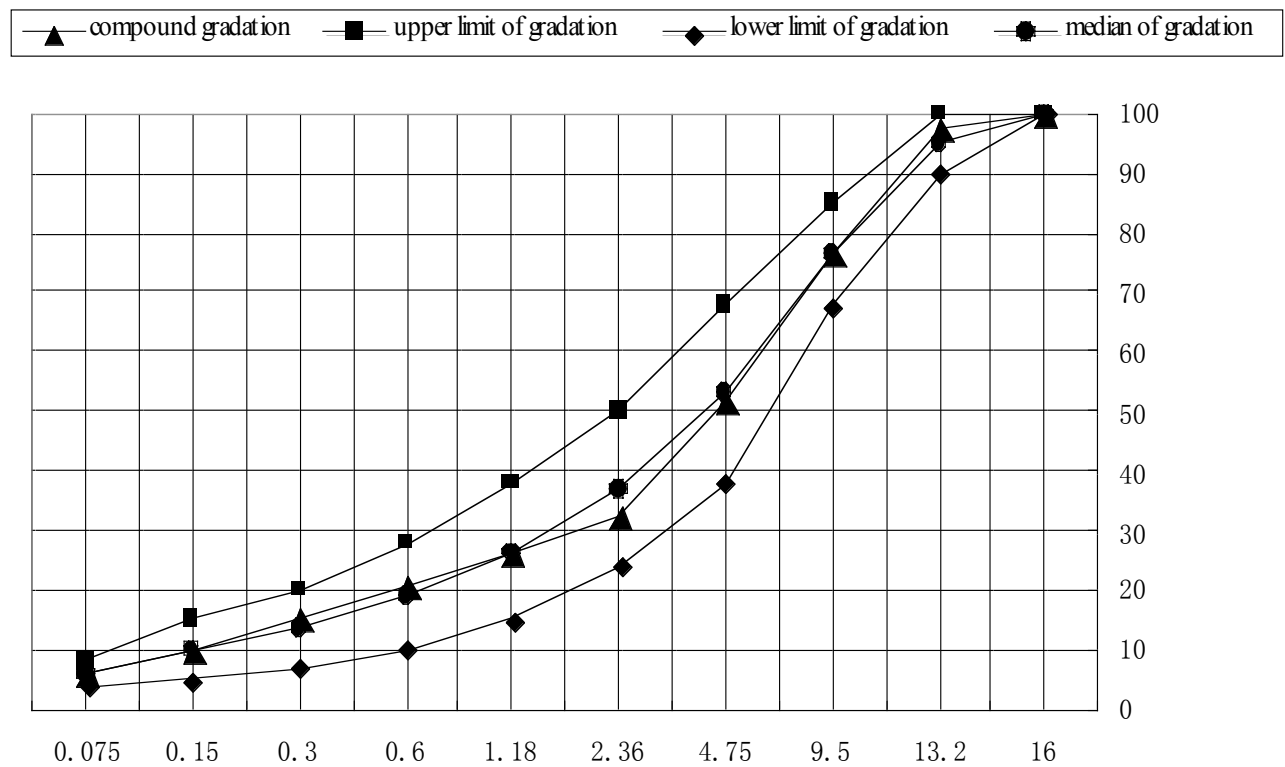

Fig. (1). 

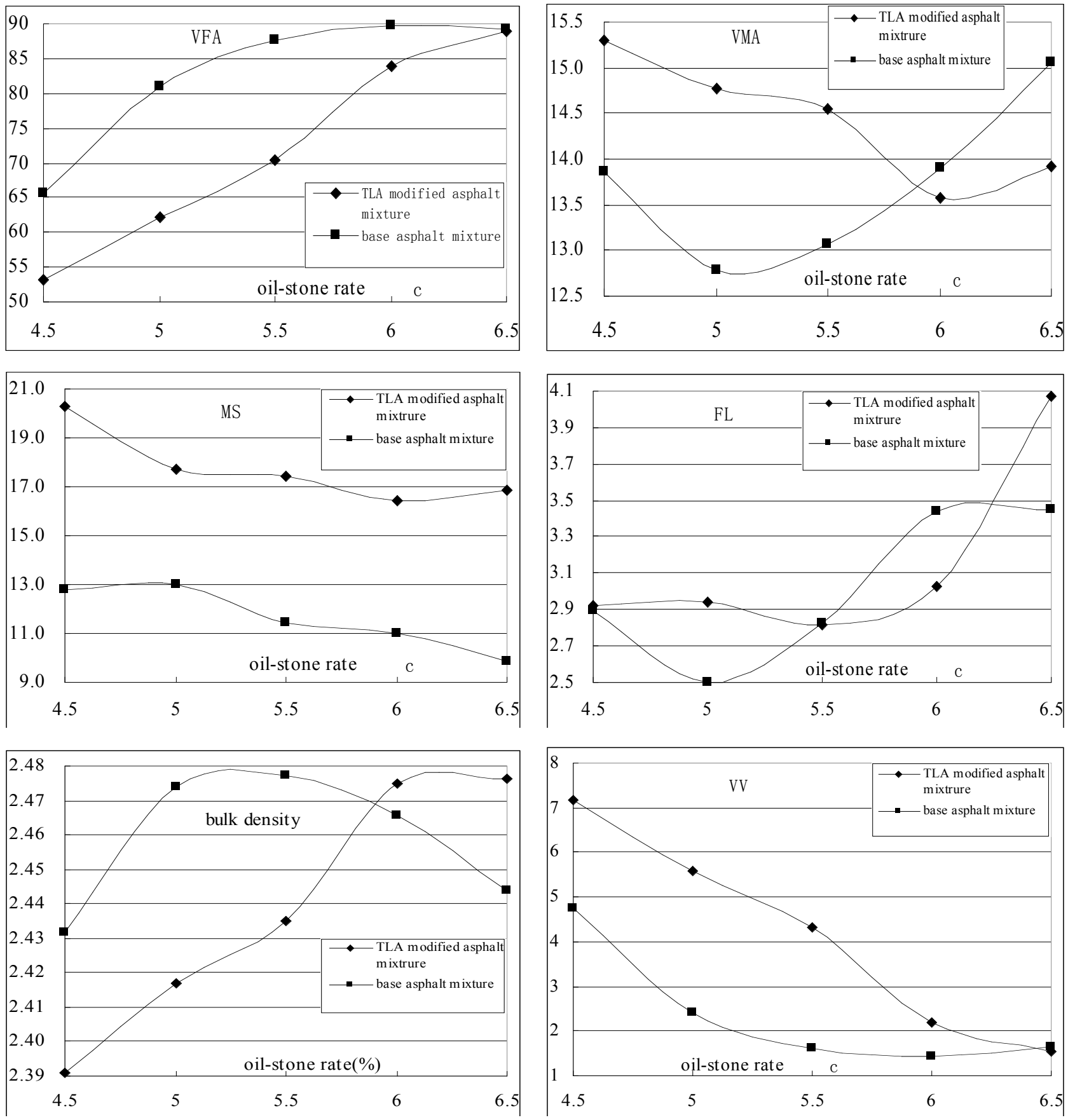

Fig. (2). The curves of physics mechanics parameter versus oil-stone rate of asphalt mixture.

were calculated. The curves of physics mechanics parameter versus oil-stone rate of two kinds of asphalt mixture are shown in Fig. (2).

Fig. (2) shows as following:

1) Marshall stability of TLA modified asphalt mixture is bigger than that of base asphalt mixture at the same oil-stone rate. Because TLA is a kind of unique natural asphalt, and it contains more gel structure than sol structure, it provides structure performance for TLA modified asphalt and reduces temperature sensitivity of TLA modified asphalt by its unique microscopic size and character of asphalting.
2) Volume of air voids of TLA modified asphalt mixture is bigger than that of base asphalt mixture, while voids filled with asphalt of TLA modified asphalt mixture is smaller than that of base asphalt mixture at the same oil-stone rate. Because TLA contains ash, asphalt content of TLA modified asphalt is less than base asphalt at the same oil-stone rate.

3) In the curves of voids in mineral aggregate versus oilstone rate and bulk density versus oil-stone rate, minimum value of voids in mineral aggregate and maximum value of bulk density of TLA modified asphalt mixture both appear latter than that of base asphalt mixture. The reason is the same as 2 . 
Table 7. Marshall Test Results of AC-13C Under the Optimum Oil-Stone Rate

\begin{tabular}{|c|c|c|c|c|}
\hline Technical Index & Unit & Base Asphalt Mixture & 40\%TLA Modified Asphalt Mixture & Technical Requirements \\
\hline Bulk density & $\mathrm{g} / \mathrm{cm}^{3}$ & 2.457 & 2.435 & - \\
\hline Theoretical maximum density & $\mathrm{g} / \mathrm{cm}^{3}$ & 2.542 & 2.545 & - \\
\hline Volume of air voids & $\%$ & 3.4 & 4.3 & $3 \sim 5$ \\
\hline Voids in mineral aggregate & $\%$ & 13.2 & 14.5 & $\geq 13 ; \geq 14$ \\
\hline Voids filled with asphalt & $\%$ & 74.9 & 70.4 & $65 \% \sim 75 \%$ \\
\hline Marshall stability & $\mathrm{kN}$ & 12.89 & 17.44 & $\geq 8$ \\
\hline Flow value & $\mathrm{mm}$ & 2.66 & 2.82 & $1.5 \sim 4$ \\
\hline Marshall modulus & $\mathrm{kN} / \mathrm{mm}$ & 4.85 & 6.18 & - \\
\hline
\end{tabular}

4) At the same oil-stone rate, the difference of flow value between TLA modified asphalt mixture and base asphalt mixture is little.

Oil-stone rates which correspond to maximum of density, maximum of Marshall Stability, target volume of air voids (or median) and median of voids filled with asphalt range is calculated according to Fig. (2), and the average of them was regarded as $\mathrm{OAC}_{1}$. The median of oil-stone rate range $\mathrm{OAC}_{\min } \sim \mathrm{OAC}_{\max }$ which each index meet technical standard (except VMA) is regarded as $\mathrm{OAC}_{2}$. Lastly the average of $\mathrm{OAC}_{1}$ and $\mathrm{OAC}_{2}$ was regarded as optimum oil-stone rate OAC. The results show that OAC of TLA modified asphalt mixture is $5.5 \%$ and $\mathrm{OAC}$ of base asphalt mixture is $4.8 \%$.

OAC of TLA modified asphalt mixture divided by that of base asphalt mixture is 1.15 , which proves that there is a transforming coefficient of 1.15 between optimum oil-stone rates of TLA modified asphalt mixture and that of base asphalt mixture. Marshall Test results of two kinds of asphalt mixture under the optimum oil-stone rate are shown in Table 7 , which meet the requirements specified specification.

\subsection{Calculation of Ultimate Compound Gradation}

$40 \%$ TLA modified asphalt mixture contains $12.8 \%$ ash, and its optimum oil-stone rate is $5.5 \%$, so ash-aggregate rate of mineral aggregate is $5.5 \% \times 12.8 \times=0.7 \%$, and composition proportion of mineral aggregate change into: $10 \sim 15 \mathrm{~mm}$ crushed stone:5 10 mm crushed stone:3 5 mm crushed stone:0 3mm stone chips:cement:ash=22/100.7:24/100.7:22/ 100.7:30/100.7:30/100.7:0.7/100.7. Gradation of ash can be regarded approximately as that $0.15 \mathrm{~mm}$ passing rate is $100 \%, 0.075 \mathrm{~mm}$ passing rate is $90 \%$, so the ultimate compound gradation of $40 \%$ TLA modified asphalt mixture is got according to Table $\mathbf{8}$.

As we can see from Table $\mathbf{8}$, because TLA modified asphalt contains ash, the ultimate compound gradation of TLA modified asphalt mixture becomes finer than previous gradation, and especially has a large influence on passing rate of the sieve sizes which are less than $2.36 \mathrm{~mm}$.

\section{EXPERIMENTAL RESEARCH ON PAVEMENT PERFORMANCE OF TLA MODIFIED ASPHALT MIXTURE}

Specimens were prepared respectively with TLA modified asphalt mixture and base asphalt mixture under the optimum oil-stone rate, and them were used to pavement performance test.

\subsection{High Temperature Stability Test}

Rutting test was used to evaluate high temperature stability of asphalt mixture, and the results are shown in Table 9. According to climate subarea of asphalt pavement in China, Foshan city of Guangdong province belongs to area of hot summer and warm winter (area 1-4), so the construction specification specifies that dynamic stability of ordinary asphalt mixture can not be smaller than 1000 times/mm, and dynamic stability of modified asphalt mixture can not be smaller than 2800 times $/ \mathrm{mm}$. Test results show that dynamic stability of two kinds of asphalt mixture both meet specification requirements. Compared with base asphalt mixture, dynamic stability of TLA modified asphalt mixture increase $285 \%$, which shows that high temperature stability of TLA modified asphalt mixture, is more excellent than that of base asphalt mixture.

\subsection{Capacity of Moisture-Resistance Damage Test}

Retained Marshall Stability test and freeze-thaw split test were used to evaluate capacity of moisture-resistance damage of asphalt mixture. Test results are shown in Tables $\mathbf{1 0}$ and 11 respectively.

According to climate sub area of asphalt pavement in China, Foshan city of Guangdong province belong to moist area, so the construction specification specifies that retained Marshall Stability of ordinary asphalt mixture can not be smaller than $80 \%$, and retained Marshall Stability of modified asphalt mixture can not be smaller than $85 \%$. The test results show that retained Marshall Stability of two kinds of asphalt mixture both meets the requirements specified specification. Retained Marshall stability of TLA modified asphalt mixture are bigger than that of base asphalt mixture, which shows that capacity of moisture-resistance damage of TLA modified asphalt mixture is better than that of base asphalt mixture.

The construction specification specifies that retained split strength ratio of ordinary asphalt mixture can not be less than $75 \%$, and retained split strength ratio of TLA modified asphalt mixture can not be less than $80 \%$ in moist area. The test results show that retained split strength ratio of two kinds of asphalt mixture both meets the requirements specified specification. Split strength ratio of TLA modified 
Table 8. Ultimate Compound Gradation of 40\% TLA Modified Asphalt Mixture AC-13C

\begin{tabular}{|c|c|c|c|c|c|c|c|c|c|c|c|}
\hline Gradation & \multicolumn{10}{|c|}{ Passing Rate (\%) } & $\begin{array}{c}\text { Proportion } \\
\text { (\%) }\end{array}$ \\
\hline $5 \sim 10 \mathrm{~mm}$ crushed stone & 100 & 100 & 87 & 2.8 & 0.7 & 0.7 & 0.7 & 0.7 & 0.7 & 0.7 & $24 / 100.7$ \\
\hline $3 \sim 5 \mathrm{~mm}$ crushed stone & 100 & 100 & 100 & 86.6 & 12.9 & 6.4 & 4.4 & 3.6 & 3.1 & 2.6 & $22 / 100.7$ \\
\hline Cement & 100 & 100 & 100 & 100 & 100 & 100 & 100 & 100 & 99.8 & 97.2 & $2 / 100.7$ \\
\hline Ash & 100 & 100 & 100 & 100 & 100 & 100 & 100 & 100 & 100 & 90 & $0.7 / 100.7$ \\
\hline Median of gradation & 100 & 95 & 76.5 & 53 & 37 & 26.5 & 19 & 13.5 & 10 & 6 & \\
\hline Compound gradation & 100 & 97.3 & 76.2 & 51.9 & 32.5 & 26.0 & 20.4 & 15.1 & 9.8 & 6.3 & 100 \\
\hline
\end{tabular}

Table 9. Rutting Test Results

\begin{tabular}{|c|c|c|c|}
\hline Kinds of Asphalt Mixture & Dynamic Stability (Times/mm) & Coefficient of Variation (\%) & Technical Requirements (Times/mm) \\
\hline \hline Base asphalt mixture & 1215 & 36.2 & 1000 \\
\hline TLA modified asphalt mixture & 4678 & 14.4 & 2800 \\
\hline
\end{tabular}

Table 10. Retained Marshall Stability Test Results

\begin{tabular}{|c|c|c|c|c|}
\hline $\begin{array}{c}\text { Kinds of Asphalt } \\
\text { Mixture }\end{array}$ & $\begin{array}{c}\text { Marshall Stability } \\
\text { MS (kN) }\end{array}$ & $\begin{array}{c}\text { Marshall stability After being } \\
\text { Immersed 48h } \mathbf{M S}_{\mathbf{1}}(\mathbf{k N})\end{array}$ & $\begin{array}{c}\text { Retained Marshall Stability } \\
\mathbf{M S}_{\mathbf{0}}(\mathbf{\%})\end{array}$ & $\begin{array}{c}\text { Technical Requirements } \\
\mathbf{M S}_{\mathbf{0}}(\mathbf{\%})\end{array}$ \\
\hline \hline Base asphalt mixture & 13.2 & 11.5 & 87.0 & $\geq 80$ \\
\hline TLA modified asphalt mixture & 16.2 & 15.2 & 93.8 & $\geq 85$ \\
\hline
\end{tabular}

asphalt mixture is bigger than that of base asphalt mixture, which shows that capacity of moisture-resistance damage of TLA modified asphalt mixture is better than that of base asphalt mixture, and TLA modified asphalt mixture has more excellent capacity of moisture-resistance damage, too.

\subsection{Permeability Test}

Permeability test were used to evaluate impermeability of asphalt mixture. Test results are shown in Table 12. The construction specification specifies that permeability coefficient can not be bigger than $120 \mathrm{ml} / \mathrm{min}$. The test results show that permeability coefficient of two kinds of asphalt mixture both meet the requirements specified specification. Permeability coefficient of TLA modified asphalt mixture is smaller than that of base asphalt mixture, which shows that impermeability of TLA modified asphalt mixture is better than that of base asphalt mixture.

Table 11. Freeze-Thaw Split Test Results

\begin{tabular}{|c|c|c|c|c|}
\hline $\begin{array}{c}\text { Kinds of Asphalt } \\
\text { Mixture }\end{array}$ & $\begin{array}{c}\text { Split Strength Before Freezing- } \\
\text { Thawing Cycle (MPa) }\end{array}$ & $\begin{array}{c}\text { Split Strength After } \\
\text { Freezing-Thawing Cycle (MPa) }\end{array}$ & $\begin{array}{c}\text { Retained Split Strength } \\
\text { Ratio TSR (\%) }\end{array}$ & $\begin{array}{c}\text { Technical Requirements } \\
\text { TSR (\%) }\end{array}$ \\
\hline \hline Base asphalt mixture & 0.94 & 0.81 & 85.6 & $\geq 75$ \\
\hline TLA modified asphalt mixture & 1.87 & 1.70 & 91.0 & $\geq 80$ \\
\hline
\end{tabular}

Table 12. Permeability Test Results

\begin{tabular}{|c|c|c|}
\hline Kinds of Asphalt Mixture & Permeability Coefficient (ml/min) & Technical Requirements (ml/min) \\
\hline \hline Base asphalt mixture & 56.7 & $\leq 120$ \\
\hline TLA modified asphalt mixture & 48.3 & \\
\hline
\end{tabular}




\section{CONCLUSIONS}

(1) Marshall stability and volume of air voids of TLA modified asphalt mixture is bigger than that of base asphalt mixture, while voids filled with asphalt of TLA modified asphalt mixture is smaller than that of base asphalt mixture at the same oil-stone rate.

(2) In the curves of voids in mineral aggregate versus oilstone rate and bulk density versus oil-stone rate, minimum value of voids in mineral aggregate and maximum value of bulk density of TLA modified asphalt mixture both appear latter than that of base asphalt mixture.

(3) There is a transforming coefficient of 1.15 between optimum oil-stone rate of $40 \%$ TLA modified asphalt mixture and that of base asphalt mixture.

(4) Because TLA modified asphalt contains ash, the ultimate compound gradation of TLA modified asphalt mixture becomes finer than previous gradation, and especially has a large influence on passing rate of the sieve sizes which are less than $2.36 \mathrm{~mm}$.

(5) TLA modified asphalt mixture has excellent high temperature stability, capacity of moisture-resistance damage and impermeability. So it can be applied to asphalt pavements engineering of expressway in China.

\section{ACKNOWLEDGEMENTS}

The authors appreciate the support of National Natural Science Foundation of China. Project No. 51078046 and Education Department of Hunan Province. Project No. $08 \mathrm{C} 058$.

\section{REFERENCES}

[1] Shen JA. Trinidad lake asphalt and its application prospect. J Foreign Highway 2000; 20(2): 28-31.

[2] Shen JA. Performance of Trinidad Lake Asphalt modified asphalt. J Foreign Highway 2000; 20(3): 30-2.

[3] Feng XJ, Hao PW, Zha XD. Optimization of aggregate gradations for modified asphalt AC-13 mixtures in pavement. J Chang'an Univ: Nat Sci Ed 2007; 27(3): 20-4.

[4] Feng XJ, Hao PW, Zha XD. Research on proportioning design of TLA asphalt modified asphalt mixture. Highway 2007; 27(4): 1705.

[5] Feng XJ, Hao PW, Zha XD. Research on road performance of TLA asphalt modified asphalt and its mixture. Highway 2007; 27(5): 161-5.

[6] Chen Q, Fu XY, et al. Experimental research on Trinidad Lake Asphalt TLA modified asphalt. Highway 2005; 25(9): 156-9.

[7] Liang HR. Application of TLA modified asphalt in guang-shao freeway pavement treatment. J Chin Foreign Highway 2005; 25(4): $182-4$.

[8] Wang GJ. Experimental research on road performance of Trinidad Lake Asphalt modified asphalt. J Highway Transport Res Dev 2008; 25(9): 32-34.

[9] Ni FJ, Lai YM, et al. Research on pavement performance of composite modified asphalt mixture with (TLA). J Highway Transport Res Dev 2005; 22(1): 13-16. 